\title{
The effects of 10 weeks of $\beta$-alanine supplementation on peak power, power drop, and lactate response in Korean national team boxers
}

\author{
Kwang-Jun Kim', Hong-Sun Song', Dong Hyun Yoon², David H. Fukuda', Soon Hee Kim4, Dong-Ho Park,** \\ 1 Division of Sports Science, Korea Institute of Sport Science, Seoul, Korea \\ ${ }^{2}$ Institute of Sports Science, Seoul National University, Seoul, Korea \\ ${ }^{3}$ Institute of Exercise Physiology and Wellness, University of Central Florida, Orlando, FL, USA \\ ${ }^{4}$ Department of Golf, Yongin University, Yongin, Korea \\ ${ }^{5}$ Department of Kinesiology, Inha University, Incheon, Korea
}

This study was designed to investigate the effects of $\beta$-alanine (BA) supplementation on peak power, power drop, and lactate response in elite male amateur boxers. Nineteen male Korean national team boxers were divided into groups with either $B A(n=9)$ or placebo $(P L, n=10)$ supplementation. BA consumed 4.9-5.4 g/day of BA with training for 10 weeks and PL took PL in a similar manner. Physical fitness and lactate changes in sparring were measured before and after the 10-week intervention. Significant interactions $(P<0.05)$ were shown for lower body peak power $(P=0.049)$ and upper body power drop $(P=0.042)$. Positive effects for the BA group were shown for lower body peak power (Cohen $d=0.72 ; 95 \%$ confidence interval [CI], 0.09-1.35) and the maintenance of upper body power output ( $d=-0.91 ; 95 \% \mathrm{Cl},-1.61$ to -0.17 ). These findings suggest that Korean national amateur boxers who consumed BA demonstrated differential responses following a training intervention in specific physical fitness when compared to boxing athletes who consumed a PL.

Keywords: $\beta$-Alanine, Training, Physical fitness, Lactate, Amateur boxer

\section{INTRODUCTION}

During high-intensity exercise, such as boxing, the human body accumulates hydrogen ions due to glycolysis which results in muscle fatigue, potentially, limiting performance (Pedersen et al., 2004). Recent research has reported positive effects on performance with supplementation of $\beta$-alanine (BA) which has become a commonly used ergogenic aid (Hobson et al., 2012). In humans, BA plays an important role as a precursor to carnosine synthesis, while increased muscle carnosine concentration serves as a physiological buffer (Batrukova and Rubtsov, 1997; Mannion et al., 1995) and possibly improves calcium sensitivity (Hannah et al., 2015). In support, athletes with low carnosine content have shown to possess insufficient anaerobic exercise capabilities (Derave et al., 2010).

When examining BA supplementation, most studies utilize short term dosing protocols with total daily intake of 6-6.4 g per day in 4 or more equal servings (Donovan et al., 2012; Hill et al., 2007; Smith et al., 2009). Four and 10 weeks of BA supplementation have shown to improve cycling performance in physicallyactive adult men (Hill et al., 2007), while the addition of highintensity interval training to 6 weeks of BA supplementation in college-aged men significantly improves cardiovascular function and endurance (Smith et al., 2009). However, in elite sprinters, no significant effects of short term (4 weeks) BA supplementation on 400-m run performance, lactate response, and oxygen deficit were reported. In a meta-analysis, Hobson et al. (2012) reported that chronic BA supplementation may further enhance sports performance, while Derave et al. (2007) has emphasized that BA supplementation can have ergogenic effects during single or repeated bouts of high-intensity exercise.
${ }^{*}$ Corresponding author: Dong-Ho Park (D) https://orcid.org/0000-0003-1863-0652 Department of Kinesiology, Inha University, 100 Inha-ro, Nam-gu, Incheon 22212, Korea

Tel: +82-32-860-8182, Fax: +82-32-860-8188, E-mail: dparkosu@inha.ac.kr Received: September 20, 2018/ Accepted: November 14, 2018
This is an Open Access article distributed under the terms of the Creative Commons Attribution Non-Commercial License (http://creativecommons.org/licenses/by-nc/4.0/) which permits unrestricted non-commercial use, distribution, and reproduction in any medium, provided the original work is properly cited. 
BA supplementation has been reported to improve exercise capacity during high-intensity exercise in both athletes (Painelli Vde et al., 2013; Tobias et al., 2013) and nonathletes (Hill et al., 2007) with similar responses regardless of training status (Painelli Vde et al., 2013). However, the results vary depending on the nature of the event and BA research related to combat sports is scarce (Donovan et al., 2012; Tobias et al., 2013). In the only such study in boxers, Donovan et al. (2012) reported that a short term (4 weeks) BA dosing protocol improved punching performance during a simulated match. In addition to punching performance, elite boxers present elevated anaerobic thresholds, as well as high levels of aerobic fitness and muscle strength (Arseneau et al., 2011). In particular, lower body muscle function has an important role in the coordination of upper body movements, both striking and defense, through the maintenance of appropriate footwork. Thus, additional examination of the effects of long-term BA supplementation on the various physical factors that benefit athletes engaging in highintensity competitive events, such as elite-level boxing, is warranted.

The rules of competitive boxing do not allow for nutrition (except water) during a match. For this reason, Donovan et al. (2012) emphasized that nutritional strategies, including the potential use of ergogenic aids, during the hours, days and weeks leading up to a match may be needed to enhance performance. Therefore, the purpose of this study was to investigate the effects of 10 weeks of BA supplementation and boxing training on physical fitness and lactate response to multiple sparring sessions in elite male amateur boxers.

\section{METERIALS AND METHODS}

\section{Participants}

Nineteen amateur male boxers who were members of the Korean national team participated in this study (Table 1). In order to account for the varying physical characteristics of the participants in this study, BA and placebo (PL) consisted of one athlete from

Table 1. Characteristics of participants in the $\beta$-alanine (BA) and placebo (PL) groups

\begin{tabular}{lcc}
\hline Variable & BA group $(\mathrm{n}=9)$ & PL group $(\mathrm{n}=10)$ \\
\hline Age $(\mathrm{yr})$ & $23.00 \pm 1.82$ & $22.20 \pm 2.21$ \\
Height $(\mathrm{cm})$ & $180.41 \pm 7.42$ & $178.59 \pm 6.33$ \\
Weight $(\mathrm{kg})$ & $77.25 \pm 20.64$ & $75.31 \pm 19.21$ \\
Body fat $(\%)$ & $12.30 \pm 7.89$ & $13.87 \pm 6.44$ \\
Body mass index $\left(\mathrm{kg} / \mathrm{m}^{2}\right)$ & $23.60 \pm 5.51$ & $24.03 \pm 4.49$ \\
Career $(\mathrm{yr})$ & $7.27 \pm 0.95$ & $7.41 \pm 0.73$ \\
\hline
\end{tabular}

Values are presented as mean \pm standard deviation. each weight division for a total of 10 athletes in each of the respective supplementation groups. During the intervention, one of the BA participants had to withdraw from the study due to injuries. Thus, the final analysis included $9 \mathrm{BA}$ athletes and $10 \mathrm{PL}$ athletes. Participants were fully informed of the testing procedure and reported to have not taken any dietary supplements, such as multivitamins or antioxidants, during the study. This study was approved by the Medical Ethics Committee of KISS (Korea Institute of Sport Science) (IRBNO: KISS13001-001-01).

\section{Procedure}

A double-blind study was performed, which consisted of two experimental testing sessions interspersed by a 10 -week training and supplementation period. National team boxers, from each of the respective weight categories, completed identical offseason training sessions, but were separated into BA or PL supplementation (PL) groups. Training was composed of power-circuit, strength, and sport-specific elastic tubing training conducted four times per week. Physical fitness, including variables accounting for strength, power, and power-endurance were measured in the exercise physiology laboratory, while lactate during and following sparring were measured in the boxing gym before and after the intervention period. All physical fitness tests were performed at the same time of day (9:00 a.m. to 1:00 p.m.). Measurement of lactate response in sparring was completed one day after the physical fitness tests.

\section{BA supplementation}

BA of $100 \%$ purity was provided as capsules made by to simplify consumption. With reference to effective supplementation strategies (4.8-6.4 g/day) in previous studies (Donovan et al., 2012; Hill et al., 2007; Kendrick et al., 2008; Sale et al., 2012), the participants were instructed to take 4.9-5.4 g/day of BA for 10 weeks. The BA group consumed BA ( $\beta$-alanine, Suzhou Vitajoy Biotech, Suzhou, China) in either 550- or 600-mg capsules ( $\beta$-alanine, POSYKO, Seoul, Korea) for the lower ( $49 \mathrm{~kg}$ to $-69 \mathrm{~kg}$ ) or higher weight categories $(-75 \mathrm{~kg}$ to $+91 \mathrm{~kg})$, respectively. The athletes were instructed to take three capsules (approximately 18$30 \mathrm{mg} / \mathrm{kg}$ ) in the morning, afternoon, evening immediately following a meal. No side effects (skin tingling, gastro-intestinal discomfort) or weight gain were reported with BA supplementation. The PL group consumed maltodextrin capsules (Samyang Genex, Seoul, Korea) in a manner similar to the BA group.

\section{Training protocol}

Routine training sessions consisting of power-circuit, strength, 
Table 2. Outline of the 10-week training program

\begin{tabular}{|c|c|}
\hline Variable & Content \\
\hline \multicolumn{2}{|c|}{ Strength \& power-circuit training } \\
\hline Goal & Improvement of strength, power \& power endurance \\
\hline Intensity \& & Strength: 70\%-80\% 1RM; 12-15 repetitions (Mon/Thu a.m.) \\
\hline No. of repetitions & Power-circuit: 60\%-70\% 1RM; 8-10 repetitions (Tue/Fri a.m.) \\
\hline Frequency & 2 times/wk \\
\hline \multicolumn{2}{|l|}{ Elastic tubing training } \\
\hline Goal & Improvement of power \& power endurance \\
\hline Intensity & Explosive rhythm (30 sec-3 min) \\
\hline Frequency & 2 times/wk (Tue/Thu p.m.) \\
\hline
\end{tabular}

1RM, one-repetition maximum; Mon, Monday; Tue, Tuesday; Thu, Thursday; Fri, Friday.

and sport-specific elastic tubing training were carried out four times a week for a total of 10 weeks. Power-circuit and strength training were carried out at the national training center for $2 \mathrm{hr}$ in the morning and sport-specific elastic tubing training was carried out at the boxing gym for $1 \mathrm{hr}$ in the afternoon (Table 2). The training program was planned through consultation with coaches and co-researchers, and designed to allow for an equal (50:50) ratio of technical and physical training components. The sport-specific elastic tubing training program included six exercises associated with boxing skills (punches [straight, hook, uppercut, combinations], torso rotations and defensive maneuvers) completed explosively in a rhythmic pattern for durations ranging from 30 sec to 3 min. Power circuit training consisted of 3 sets of $8-10$ repetitions of 8 exercises, sandbag punching, squats, power weaving, hard stepping, tubing punching, incline sit ups, deadlifts, and tubing pulling completed at $60 \%-70 \%$ one-repetition maximum (1RM) or explosively in a rhythmic pattern. Treadmill running at $50 \%$ of maximal heart rate was used as a dynamic recovery between exercises. Strength training consisted of 12-15 repetitions of 10 exercises, including leg extension, bench press, seated calf raise, back hyperextension, lateral raise, cable crunch, wrist curl, arm pull down, back squat and shoulder press completed at 70\%-80\% 1RM.

\section{Pre- and posttest measurements}

Standing height was measured with a stadiometer (TBF-202, Tanita, Tokyo, Japan) while body mass and body fat percentage were measured in duplicate in the morning following a 12-hr fast with a multifrequency bioimpedance analyzer (InBody 720, Biospace, Seoul, Korea).

Prior to and following the 10-week training and supplementation period, physical fitness, including isotonic strength (bench press and back squat), isokinetic strength (leg and trunk), muscular power (Sargent jump, upper/lower body peak/mean power from Wingate anaerobic testing), power-endurance (repeated jumping, situps, pushups, upper/lower body power drop from Wingate anaerobic testing) and lactate response to sparring were measured.

Isotonic maximal strength was measured via bench press and back squat using an ACES Multi-Function 2000 (Ariel Dynamics Inc., Lake Forest, CA, USA). After sufficient warm-up, participants attempted a self-selected number of submaximal trials to establish the appropriate ranges of motion. The concentric phase of the lifts were completed at an angular velocity of $10^{\circ} / \mathrm{sec}$, while the eccentric phases were completed at $200^{\circ} / \mathrm{sec}$. Once the range of motion was established, the maximal weight lifted in $\mathrm{kg}$ was established.

Isokinetic strength was measured using a Humac Norm dynamometer (Computer Sports Medicine, Inc, Stoughton, MA, USA). Trunk strength was recorded at an angular velocity of $30 \% \mathrm{sec}$, while leg strength was recorded for both the left and right legs at an angular velocity of $60 \%$ sec. Once the posture adjustment and equipment settings were completed, participants performed 3 maximal flexion and extension movements to measure peak torque.

The 30-sec Wingate anaerobic test was conducted by using an arm ergometer (LODE, Brachumera Sports, Groningen, The Netherlands) and a cycle ergometer ergometer (Ergomedic 894E, Monark, Vansbro, Sweden). Participants warmed up by pedaling for less than $3 \mathrm{~min}$ at 50-60 rpm on the arm or cycle ergometer against a self-selected resistance. During the testing procedures, resistance was set to $0.7 \mathrm{Nm} \times$ body weight $(\mathrm{kg})$ and 0.075 $\mathrm{Kp} \times$ body weight $(\mathrm{kg})$ for the arm and cycle ergometers, respectively. Peak power, mean power, and power drop ([peak power-minimum power $] /$ peak power $\times 100$ ) were calculated for both the upper and lower extremities.

A Sargent jump test was used to measure the maximum jump height with a jump meter (TKK 1228, Takei, Yokohama, Japan). Following a brief warmup, the participant's standing reach height with one hand was measured. Participants then completed two maximal jumping trials by starting from a static position and reaching as high as possible with one arm on the jump meter board. The greatest distance between the standing reach height and the jump height values was recorded. A 1-min repeated jump was used to examine lower body muscular endurance. Participants were instructed to jump and touch a target $30 \mathrm{~cm}$ above their standing height. The number of times the target was successfully 
Table 3. Physical fitness variables for the $\beta$-alanine (BA) and placebo (PL) prior to (pre) and following (post) 10-weeks of $\beta$-alanine supplementation

\begin{tabular}{|c|c|c|c|c|}
\hline Physical fitness & Group & Pre & Post & $P$-value \\
\hline \multicolumn{5}{|l|}{ Maximal strength } \\
\hline \multirow[t]{3}{*}{ Bench press (kg) } & $\mathrm{BA}$ & $83.55 \pm 22.86$ & $87.88 \pm 24.29$ & a: 0.302 \\
\hline & $\mathrm{PL}$ & $83.30 \pm 23.08$ & $82.80 \pm 19.33$ & b: 0.795 \\
\hline & & & & $a \times b: 0.197$ \\
\hline \multirow[t]{3}{*}{ Squat (kg) } & $\mathrm{BA}$ & $160.77 \pm 38.59$ & $167.55 \pm 48.84$ & a: 0.404 \\
\hline & $P L$ & $153.20 \pm 36.95$ & $157.60 \pm 23.28$ & b: 0.591 \\
\hline & & & & $a \times b: 0.858$ \\
\hline \multicolumn{5}{|l|}{ Isokinetic strength } \\
\hline \multirow{3}{*}{$\begin{array}{l}\text { Knee flexion (right) } \\
\text { (\%BW) }\end{array}$} & BA & $153.24 \pm 14.53$ & $157.24 \pm 11.44$ & a: 0.411 \\
\hline & $\mathrm{PL}$ & $148.96 \pm 15.57$ & $150.57 \pm 14.05$ & b: 0.385 \\
\hline & & & & $a \times b: 0.723$ \\
\hline \multirow{3}{*}{$\begin{array}{l}\text { Knee extension (right) } \\
\text { (\%BW) }\end{array}$} & $\mathrm{BA}$ & $278.07 \pm 34.88$ & $282.33 \pm 32.55$ & a: 0.536 \\
\hline & $P L$ & $276.26 \pm 38.16$ & $277.71 \pm 36.37$ & b: 0.841 \\
\hline & & & & $a \times b: 0.760$ \\
\hline \multirow{3}{*}{$\begin{array}{l}\text { Knee flexion (left) } \\
\text { (\%BW) }\end{array}$} & BA & $146.79 \pm 21.19$ & $149.82 \pm 20.40$ & a: 0.432 \\
\hline & $\mathrm{PL}$ & $142.04 \pm 17.21$ & $145.18 \pm 20.54$ & b: 0.578 \\
\hline & & & & $a \times b: 0.989$ \\
\hline \multirow{3}{*}{$\begin{array}{l}\text { Knee extension (left) } \\
\text { (\%BW) }\end{array}$} & BA & $260.99 \pm 40.40$ & $280.78 \pm 32.61$ & a: $0.043^{*}$ \\
\hline & $P L$ & $254.01 \pm 18.63$ & $269.95 \pm 33.03$ & b: 0.474 \\
\hline & & & & $a \times b: 0.816$ \\
\hline \multirow[t]{3}{*}{ Trunk flexion (\%BW) } & $\mathrm{BA}$ & $368.76 \pm 60.94$ & $370.79 \pm 58.06$ & a: 0.850 \\
\hline & $P L$ & $351.34 \pm 31.05$ & $352.50 \pm 50.10$ & b: 0.425 \\
\hline & & & & $a \times b: 0.959$ \\
\hline \multirow[t]{3}{*}{ Trunk extension (\%BW) } & BA & $417.07 \pm 53.15$ & $421.51 \pm 82.96$ & a: 0.832 \\
\hline & $P L$ & $399.22 \pm 63.65$ & $399.11 \pm 58.74$ & b: 0.486 \\
\hline & & & & $a \times b: 0.824$ \\
\hline \multicolumn{5}{|l|}{ Muscle power } \\
\hline \multirow[t]{3}{*}{ Sargent jump (cm) } & BA & $51.77 \pm 7.74$ & $55.11 \pm 8.70$ & a: $0.040^{*}$ \\
\hline & $\mathrm{PL}$ & $49.30 \pm 6.18$ & $51.00 \pm 3.71$ & b: 0.271 \\
\hline & & & & $a \times b: 0.480$ \\
\hline \multirow{3}{*}{$\begin{array}{l}\text { Peak power (lower) } \\
\text { (w/kg) }\end{array}$} & BA & $8.25 \pm 1.28$ & $8.75 \pm 0.91$ & a: 0.398 \\
\hline & $P L$ & $8.44 \pm 0.54$ & $8.24 \pm 0.30$ & b: 0.633 \\
\hline & & & & $a \times b: 0.049^{*}$ \\
\hline \multirow{3}{*}{$\begin{array}{l}\text { Peak power (upper) } \\
\text { (w/kg) }\end{array}$} & BA & $13.14 \pm 2.08$ & $13.75 \pm 2.65$ & a: 0.260 \\
\hline & $\mathrm{PL}$ & $13.66 \pm 1.69$ & $13.90 \pm 1.47$ & b: 0.697 \\
\hline & & & & $a \times b: 0.615$ \\
\hline \multirow{3}{*}{$\begin{array}{l}\text { Mean power (lower) } \\
\text { (w/kg) }\end{array}$} & BA & $6.70 \pm 0.63$ & $6.82 \pm 0.65$ & a: 0.854 \\
\hline & $\mathrm{PL}$ & $6.83 \pm 0.88$ & $6.66 \pm 0.53$ & b: 0.954 \\
\hline & & & & $a \times b: 0.400$ \\
\hline \multirow{3}{*}{$\begin{array}{l}\text { Mean power (upper) } \\
\text { (w/kg) }\end{array}$} & BA & $4.57 \pm 0.81$ & $4.74 \pm 0.40$ & a: 0.392 \\
\hline & $\mathrm{PL}$ & $4.44 \pm 0.93$ & $4.51 \pm 0.67$ & b: 0.568 \\
\hline & & & & $a \times b: 0.736$ \\
\hline \multicolumn{5}{|l|}{ Power endurance } \\
\hline \multirow[t]{3}{*}{ Sit up (times/min) } & BA & $52.33 \pm 7.24$ & $52.11 \pm 7.88$ & a: 0.362 \\
\hline & $\mathrm{PL}$ & $48.10 \pm 3.60$ & $50.90 \pm 6.87$ & b: 0.322 \\
\hline & & & & $a \times b: 0.287$ \\
\hline
\end{tabular}

(Continued to the next)
Table 3. Continued

\begin{tabular}{lcccr}
\hline Physical fitness & Group & Pre & Post & \multicolumn{1}{c}{ P-value } \\
\hline Push up (times/min) & BA & $56.88 \pm 14.03$ & $59.00 \pm 14.88$ & a: 0.650 \\
& PL & $63.50 \pm 8.79$ & $63.80 \pm 14.34$ & b: 0.311 \\
& & & & axb: 0.733 \\
$\begin{array}{c}\text { Repeated jump } \\
\text { (times/min) }\end{array}$ & BA & $92.77 \pm 10.29$ & $94.33 \pm 7.28$ & a: 0.991 \\
& PL & $93.10 \pm 12.09$ & $91.60 \pm 7.60$ & b: 0.747 \\
$\begin{array}{l}\text { Power drop (lower) } \\
\text { (\%) }\end{array}$ & BA & $53.21 \pm 2.99$ & $50.13 \pm 8.20$ & a: 0.579 \\
& PL & $50.05 \pm 6.46$ & $51.11 \pm 5.25$ & b: 0.612 \\
$\begin{array}{l}\text { Power drop (upper) } \\
\text { (\%) }\end{array}$ & BA & $82.28 \pm 6.32$ & $79.66 \pm 6.17$ & a: 0.743 \\
& PL & $80.27 \pm 6.86$ & $83.82 \pm 5.79$ & b: 0.676 \\
& & & & a $\times$ b: $0.042^{*}$ \\
\hline
\end{tabular}

a, time; b, group; $a \times b$, time $\times$ group interaction; BW, body weight.

${ }^{*} P<0.05$.

Power drop=(peak power-minimum power $) /$ peak power $\times 100$.

touched during a 1-min period was recorded. Additional muscular endurance tests included the maximal number of elevated pushups (with hands on a $30 \mathrm{~cm}$ stand with a horizontal bar located at chest level and feet on the ground) and sit-ups completed in a 1 -min period.

Lactate response was investigated during a 3-round 3-min sparring session interspersed with 1-min rest periods in an effort to simulate a competitive boxing match. Each sparring session was conducted as a formal competition and refereed by the head coach who was also a certified international referee. Capillary blood samples were taken from the finger at rest, following each sparring round after removal of the boxing gloves, and at 3, 5, and $15 \mathrm{~min}$ following the simulated boxing match. Lactate concentrations were determined with a YSI-1500 analyzer (YSI Life Sciences, Yellow Springs, OH, USA).

\section{Statistical analysis}

All data were analyzed using IBM SPSS ver. 18.0 (IBM Co., Armonk, NY, USA). A $2 \times 2$ general linear model repeated-measures analysis of variance (ANOVA) was used to evaluate isotonic maximal strength, isokinetic strength, muscle power and power endurance with "group" (PL vs. BA) as a between-subjects factor and "time" (baseline vs. 10 weeks) as a within-subjects factor. Effect sizes for pre-post changes between groups were calculated as Cohen $d$ with corresponding $90 \%$ confidence intervals (CIs) and interpreted as trivial $(<0.2)$, small $(0.2-0.6)$, moderate $(0.6-1.2)$, and large (1.2-2.0) (Batterham and Hopkins, 2006). Effect size and corresponding CIs were analyzed using a custom spreadsheet. When confidence limits crossed both thresholds for substantially 
Table 4. Blood lactate concentrations (in mmol/L; mean $\pm \mathrm{SD}$ ) during sparring and recovery for the $\beta$-alanine (BA) and placebo (PL) prior to (pre) and following (post) 10 weeks of $\beta$-alanine supplementation

\begin{tabular}{|c|c|c|c|c|c|c|c|c|c|}
\hline \multirow{2}{*}{ Group } & \multirow{2}{*}{ Treatment } & \multirow{2}{*}{ Rest } & \multicolumn{3}{|c|}{ Sparring } & \multicolumn{3}{|c|}{ Recovery } & \multirow{2}{*}{ Posthoc } \\
\hline & & & After 1st round & After 2 nd round & After 3rd round & $3 \min$ & $5 \min$ & $15 \min$ & \\
\hline \multirow[t]{3}{*}{$\mathrm{BA}$} & Pre & $1.86 \pm 0.36$ & $6.93 \pm 1.47^{\mathrm{a}, \mathrm{c}, \mathrm{d})}$ & $9.17 \pm 1.37^{a, b, g)}$ & $9.99 \pm 1.48^{\mathrm{a}, \mathrm{e}, \mathrm{fg})}$ & $8.99 \pm 1.82^{a, f, g)}$ & $8.35 \pm 1.70^{a, e, g)}$ & $5.23 \pm 1.38^{\text {a) }}$ & a: 0.329 \\
\hline & Post & $1.88 \pm 0.33$ & $7.80 \pm 2.69^{\mathrm{a}, \mathrm{d})}$ & $9.80 \pm 3.33^{\mathrm{a}, \mathrm{d}, \mathrm{g})}$ & $11.63 \pm 4.02^{a, b, c, g)}$ & $9.43 \pm 2.90^{\mathrm{a}, \mathrm{g})}$ & $8.91 \pm 2.78^{a)}$ & $6.55 \pm 3.14^{a)}$ & b: 0.004 \\
\hline & & & & & & & & & $a \times b: 0.171$ \\
\hline \multirow[t]{3}{*}{$P L$} & Pre & $2.06 \pm 0.41$ & $6.99 \pm 1.27^{\mathrm{a}, \mathrm{d})}$ & $8.74 \pm 2.12^{\mathrm{a}, \mathrm{g})}$ & $9.66 \pm 2.40^{\mathrm{a}, \mathrm{e}, \mathrm{fg})}$ & $8.31 \pm 2.48^{\mathrm{a}, \mathrm{fg} g}$ & $7.41 \pm 2.18^{a, g)}$ & $5.20 \pm 1.73^{\mathrm{a})}$ & a: 0.137 \\
\hline & Post & $2.15 \pm 0.46$ & $8.02 \pm 1.92^{\mathrm{a}, \mathrm{c}, \mathrm{d}, \mathrm{g})}$ & $10.00 \pm 2.62^{\mathrm{a}, \mathrm{b}, \mathrm{g})}$ & $10.94 \pm 2.88^{a, b, e, f, g)}$ & $9.76 \pm 3.27^{\mathrm{a}, \mathrm{fg} \mathrm{g})}$ & $9.21 \pm 3.22^{\mathrm{a}, \mathrm{g})}$ & $5.97 \pm 2.53^{\mathrm{a})}$ & b: 0.001 \\
\hline & & & & & & & & & $a \times b: 0.708$ \\
\hline
\end{tabular}

a, treatment (pre vs. post); $b$, measuring point; $a \times b$, treatment $\times$ measuring point interaction.

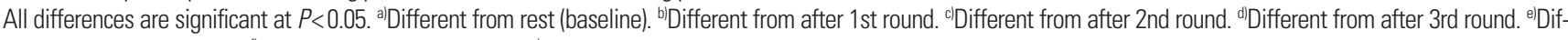
ferent from 3-min recovery. ${ }^{\text {f }}$ Different from 5 -min recovery. ${ }^{9}$ Different from 15 -min recovery.

positive $(\geq 0.20)$ and negative $(\leq-0.20)$ effects, differences were considered unclear. In addition, blood lactate concentrations was evaluated with a 2 (time: pre- vs. postsupplementation) $\times 7$ (measuring point: rest, 3 rounds and 3 periods of recovery) repeatedmeasures ANOVA for each group (PL and BA). Bonferroni tests were used for post hoc analyses. Values are presented as means \pm standard deviation, and significance was assumed at $P<0.05$.

\section{RESULTS}

\section{Change of specific physical fitness}

A significant time $\times$ group interaction $(P<0.05)$ was shown for lower body peak power and upper body power drop (Table 3). Moderate effects for both lower body peak power $(d=0.72 ; 95 \%$ CI, 0.09-1.35) and upper body power drop $(d=-0.91 ; 95 \% \mathrm{CI}$, -1.61 to -0.17 ) were noted, indicating improvements in the BA group as compared to the PL group following the 10-week intervention. A significant main effect for time was shown for left isokinetic knee extension strength and Sargent jump height $(P<$ $0.05)$. While no significant differences were detected between groups, changes in the BA group tended to be greater than changes in the PL group for both left isokinetic knee extension strength and sergeant jump. No significant interactions or main effects were noted for any of the other specific physical fitness variables.

\section{Change of lactate}

No time $\times$ measuring point interactions for changes in lactate were detected following the three rounds of sparring or during the recovery period. However, a significant main effect for measuring point was shown for both the BA $(P<0.004)$ and PL $(P<0.001)$ groups. While no significant differences were detected between groups (Table 4).

\section{DISCUSSION}

The results of the current investigation provide potential support for the use of BA in elite male amateur boxing athletes during periods of training. Divergent responses between the BA and PL groups were found in physical fitness measures and the physiological response to simulated sparring. Specifically, positive effects for the BA group were shown for lower body peak power, and the maintenance of upper body power output. In a recent meta-analysis on the performance effects of BA supplementation, Hobson et al. (2014) reported a median overall positive improvement of $2.85 \%$. In support, the BA group in the current study showed significant improvements in lower body peak power (6.06\%) and upper body power drop (3.20\%) as wells as non-significant improvements in squat (4.21\%) and bench press (5.18\%) maximal strength which exceed this value. BA purportedly acts as an important intracellular buffer in skeletal muscle (Baguet et al., 2010) and a 4-week supplementation protocol has shown to improve both punch force and frequency in amateur boxers (Donovan et al., 2012). Tobias et al. (2013) reported enhanced upper-body intermittent performance in judo and jiu-jitsu athletes using a slightly higher daily dosage (6.4 g per day) of BA after 4 weeks. Lower body peak power output improvement (ranging from $11 \%-16 \%$ ) in response to BA supplementation has also been demonstrated in both recreationally active men and elite-level athletes. Increased carnosine concentration by BA supplementation acts as a $\mathrm{Ca}++$ sensitizer within the sarcomeres (Dutka and Lamb, 2004; Lamont and Miller, 1992) and thus could prevent fatigue (Rubtsov, 2001). Furthermore, BA supplementation has been shown to increase phosphocreatine muscle stores to aid in ATP resynthesis during high intensity exercise (Harris et al., 1992). Interestingly, the time to complete 2,000-m rowing er- 
gometer trials, which lasts slightly longer than rounds in boxing, may be decreased with BA supplementation (Baguet et al., 2010; Hobson et al., 2014). While not characterized in the current investigation, improvements in training volume and decreased perception of effort with BA, as reported by Hoffman et al. (2008), may have cumulatively resulted in the small and moderate effects noted in physical fitness measures. With the knowledge that top level boxers exhibit superior anaerobic capabilities, improvements in these measures through a combination of training and BA supplementation in well-trained combat sports athletes may be of particular relevance.

Sparring is an important training element in amateur boxing for practical simulations of real competition. The duration and intensity of typical sparring sessions clearly rely on high glycolytic flux (Donovan et al., 2012) and result in oxygen uptake corresponding to approximately $70 \%$ of peak values (Arseneau et al., 2011). Physiological responses to amateur boxing include heart rate values potentially reaching $95 \%$ of maximal levels and blood lactate concentrations ranging from $6.7-17.7 \mathrm{mmol} / \mathrm{L}$ (Smith, 2006), thus demonstrating both the aerobic and anaerobic demands required to attain high levels of boxing-specific performance, such as maintaining a high frequency of powerful attacks (Donovan et al., 2012). Similarly, the lactate response to sparring in the current study resulted in blood lactate concentrations of 10-12 mmol/L (Fig. 1).

In the only published examination of BA supplementation in boxers, Donovan et al. (2012) showed increased blood lactate concentrations following a simulated match when compared to PL, while the judo and jiu-jitsu athletes in the Tobias et al. (2013) study had greater postexercise lactate values following repeated upper body Wingate testing. The results of the current investigation provide insight into the time course of lactate accumulation during multiple rounds of sparring and its subsequent clearance. As suggested by Van Thienen et al. (2009), enhanced buffering capacity should allow for enhanced glycolytic energy production and result in an overall increase in lactate production. BA supplementation has been shown to increase muscle carnosine levels, which can act maintain $\mathrm{pH}$ levels in the active muscles during high-intensity exercise (Derave et al., 2007; Harris et al., 2006; Hill et al., 2007). Thus, BA supplementation would be expected to attenuate reductions in boxing performance by slowing the development of metabolic acidosis. While the findings of the current study do not fully support this hypothesis, considerations should be given to the relatively uncontrolled nature of sparring or simulated boxing competition and qualitative evaluation of the peak lactate concentrations (following the 3rd round) which appeared to be greatest in the $\mathrm{BA}$ group following the intervention period (Fig. 1).

Contrary to former studies, which reported parasthesia for single doses of BA greater than $800 \mathrm{mg}$ (Artioli et al., 2010), no side effects were reported in the current investigation. However, side effects may differ depending on a number of factors, including racial background (Macphee et al., 2013). Finally, Sale et al. (2010) and Derave et al. (2007) emphasized that more studies need to be conducted in elite athletes and different sporting environments in order to gain a clear understanding of the value of BA supplementation for performance enhancement. The results of this study combined with previous research in combat sports provide mean-

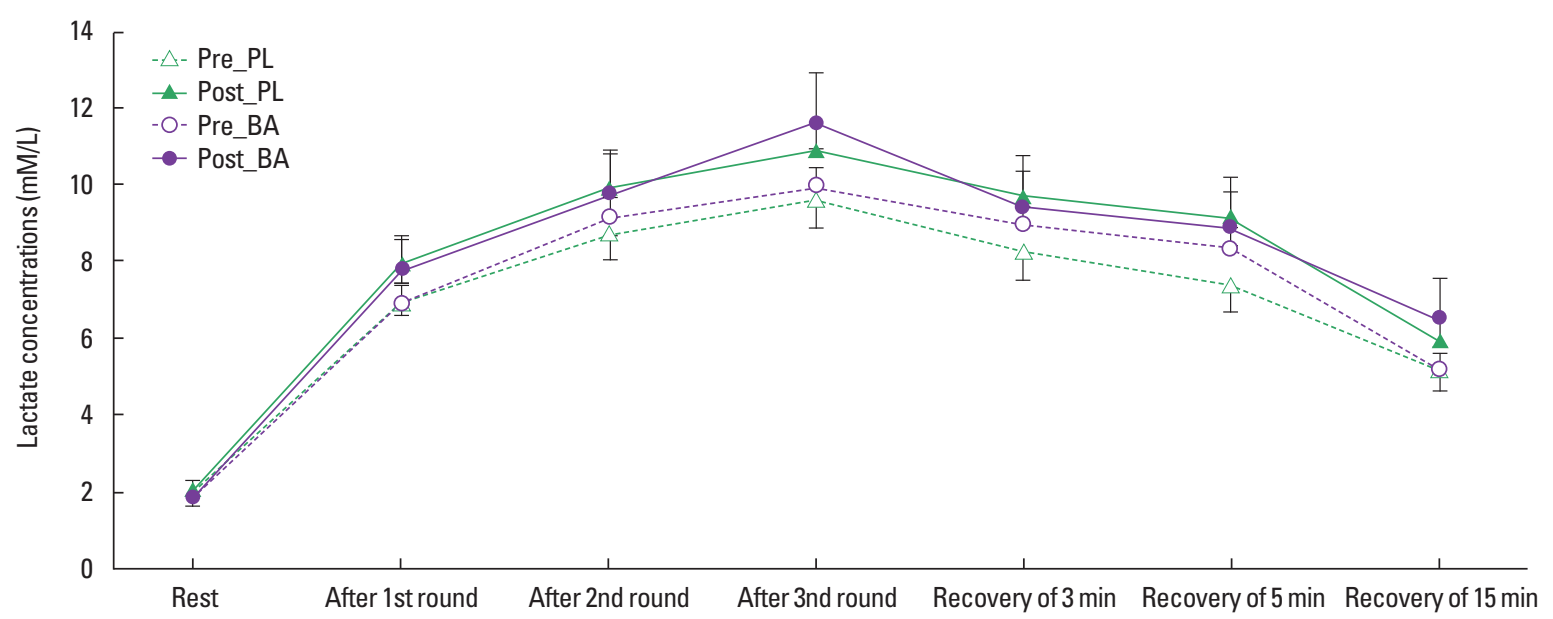

Fig. 1. The change of lactate concentrations (in mmol/L) during sparring and recovery for the $\beta$-alanine (BA) and placebo (PL) prior to (pre) and following (post) 10 weeks of BA supplementation. Both groups showed the high level of lactate after the 3rd round in sparring, particularly BA showed the highest lactate level since the BA supplementation. 
ingful information to both athletes and training staff while demonstrating the need for additional research in this population, including comparisons involving race, gender, and competitive level.

A 10-week BA supplementation protocol completed in conjunction with training significantly enhanced upper and lower body performance in elite male amateur boxing athletes. Furthermore, with no apparent negative side effects or weight gain, this supplement may be particularly useful in combat sports athletes concerned with weight management and intensive technical-tactical training programs. Therefore, this study supports the effect of long-term BA supplementation as a safe method for increasing power, power endurance, and fatigue recovery in elite male amateur boxers.

\section{CONFLICT OF INTEREST}

No potential conflict of interest relevant to this article was reported.

\section{REFERENCES}

Arseneau E, Mekary S, Léger LA. $\mathrm{VO}_{2}$ requirements of boxing exercises. J Strength Cond Res 2011;25:348-359.

Artioli GG, Gualano B, Smith A, Stout J, Lancha AH Jr. Role of $\beta$-alanine supplementation on muscle carnosine and exercise performance. Med Sci Sports Exerc 2010;42:1162-1173.

Baguet A, Bourgois J, Vanhee L, Achten E, Derave W. Important role of muscle carnosine in rowing performance. J Appl Physiol (1985) 2010; 109:1096-1101.

Batrukova MA, Rubtsov AM. Histidine-containing dipeptides as endogenous regulators of the activity of sarcoplasmic reticulum Ca-release channels. Biochim Biophys Acta 1997;1324:142-150.

Batterham AM, Hopkins WG. Making meaningful inferences about magnitudes. Int J Sports Physiol Perform 2006;1:50-57.

Derave W, Everaert I, Beeckman S, Baguet A. Muscle carnosine metabolism and $\beta$-alanine supplementation in relation to exercise and training. Sports Med 2010;40:247-263.

Derave W, Ozdemir MS, Harris RC, Pottier A, Reyngoudt H, Koppo K, Wise JA, Achten E. $\beta$-alanine supplementation augments muscle carnosine content and attenuates fatigue during repeated isokinetic contraction bouts in trained sprinters. J Appl Physiol (1985) 2007;103: 1736-1743.

Donovan T, Ballam T, Morton JP, Close GL. $\beta$-alanine improves punch force and frequency in amateur boxers during a simulated contest. Int
J Sport Nutr Exerc Metab 2012;22:331-337.

Dutka TL, Lamb GD. Effect of carnosine on excitation-contraction coupling in mechanically-skinned rat skeletal muscle. J Muscle Res Cell Motil 2004;25:203-213.

Hannah R, Stannard RL, Minshull C, Artioli GG, Harris RC, Sale C. $\beta$-Alanine supplementation enhances human skeletal muscle relaxation speed but not force production capacity. J Appl Physiol (1985) 2015; 118:604-612.

Harris RC, Söderlund K, Hultman E. Elevation of creatine in resting and exercised muscle of normal subjects by creatine supplementation. Clin Sci (Lond) 1992;83:367-374.

Harris RC, Tallon MJ, Dunnett M, Boobis L, Coakley J, Kim HJ, Fallowfield JL, Hill CA, Sale C, Wise JA. The absorption of orally supplied $\beta$-alanine and its effect on muscle carnosine synthesis in human vastus lateralis. Amino Acids 2006;30:279-289.

Hill CA, Harris RC, Kim HJ, Harris BD, Sale C, Boobis LH, Kim CK, Wise JA. Influence of $\beta$-alanine supplementation on skeletal muscle carnosine concentrations and high intensity cycling capacity. Amino Acids 2007;32:225-233.

Hobson RM, Harris RC, Martin D, Smith P, Macklin B, Elliott-Sale KJ, Sale C. Effect of sodium bicarbonate supplementation on 2000-m rowing performance. Int J Sports Physiol Perform 2014;9:139-144.

Hobson RM, Saunders B, Ball G, Harris RC, Sale C. Effects of $\beta$-alanine supplementation on exercise performance: a meta-analysis. Amino Acids 2012;43:25-37.

Hoffman JR, Ratamess NA, Faigenbaum AD, Ross R, Kang J, Stout JR, Wise JA. Short-duration $\beta$-alanine supplementation increases training volume and reduces subjective feelings of fatigue in college football players. Nutr Res 2008;28:31-35.

Kendrick IP, Harris RC, Kim HJ, Kim CK, Dang VH, Lam TQ, Bui TT, Smith M, Wise JA. The effects of 10 weeks of resistance training combined with beta-alanine supplementation on whole body strength, force production, muscular endurance and body composition. Amino Acids 2008;34:547-554.

Lamont C, Miller DJ. Calcium sensitizing action of carnosine and other endogenous imidazoles in chemically skinned striated muscle. J Physiol 1992;454:421-434.

Macphee S, Weaver IN, Weaver DF. An evaluation of interindividual responses to the orally administered neurotransmitter $\beta$-alanine. J Amino Acids 2013;2013:429847.

Mannion AF, Jakeman PM, Willan PL. Skeletal muscle buffer value, fibre type distribution and high intensity exercise performance in man. Exp Physiol 1995;80:89-101.

Painelli Vde S, Roschel H, Jesus Fd, Sale C, Harris RC, Solis MY, Benatti FB, Gualano B, Lancha AH Jr, Artioli GG. The ergogenic effect of be- 
ta-alanine combined with sodium bicarbonate on high-intensity swimming performance. Appl Physiol Nutr Metab 2013;38:525-532.

Pedersen TH, Nielsen OB, Lamb GD, Stephenson DG. Intracellular acidosis enhances the excitability of working muscle. Science 2004;305:11441147.

Rubtsov AM. Molecular mechanisms of regulation of the activity of sarcoplasmic reticulum Ca-release channels (ryanodine receptors), muscle fatigue, and Severin's phenomenon. Biochemistry (Mosc) 2001;66: 1132-1143.

Sale C, Hill CA, Ponte J, Harris RC. $\beta$-alanine supplementation improves isometric endurance of the knee extensor muscles. J Int Soc Sports Nutr 2012;9:26

Sale C, Saunders B, Harris RC. Effect of beta-alanine supplementation on muscle carnosine concentrations and exercise performance. Amino Acids 2010;39:321-333.
Smith AE, Walter AA, Graef JL, Kendall KL, Moon JR, Lockwood CM, Fukuda DH, Beck TW, Cramer JT, Stout JR. Effects of $\beta$-alanine supplementation and high-intensity interval training on endurance performance and body composition in men; a double-blind trial. J Int Soc Sports Nutr 2009;6:5.

Smith MS. Physiological profile of senior and junior England international amateur boxers. J Sports Sci Med 2006;5(CSSI):74-89.

Tobias G, Benatti FB, de Salles Painelli V, Roschel H, Gualano B, Sale C, Harris RC, Lancha AH Jr, Artioli GG. Additive effects of beta-alanine and sodium bicarbonate on upper-body intermittent performance. Amino Acids 2013;45:309-317.

Van Thienen R, Van Proeyen K, Vanden Eynde B, Puype J, Lefere T, Hespel P. $\beta$-alanine improves sprint performance in endurance cycling. Med Sci Sports Exerc 2009;41:898-903. 